\title{
Epidermal Growth Factor Receptor and Its Role in Pancreatic Cancer Treatment Mediated by Nanoparticles
}

This article was published in the following Dove Press journal: International Journal of Nanomedicine

\author{
Cristiana Maria Grapa',* \\ Teodora Mocan (D) ${ }^{1,2, *}$ \\ Diana Gonciar ${ }^{1,3, *}$ \\ Claudiu Zdrehus $\mathbb{D}^{1,3, *}$ \\ Ofelia Mosteanu ${ }^{1,3, *}$ \\ Teodora Pop ${ }^{1, *}$ \\ Lucian Mocan ${ }^{1,3, *}$
}

'Nanomedicine Department, Regional Institute of Gastroenterology and Hepatology "Prof. Dr. Octavian Fodor", Cluj-Napoca, Romania; ${ }^{2}$ Physiology Department, "Iuliu Hatieganu" University of Medicine and Pharmacy, Cluj-Napoca, Romania; ${ }^{3} 3$ rd Surgery Clinic, "Iuliu Hatieganu" University of Medicine and Pharmacy, Cluj-Napoca, Romania

*All authors contributed equally to this work

Correspondence: Teodora Mocan Physiology Department, "Iuliu Hatieganu" University of Medicine and Pharmacy, I

Clinicilor Street, Cluj-Napoca 40006,

Romania

Tel +40264598575

$\mathrm{Fax}+40264599814$

Email teodora.mocan@umfcluj.ro

\begin{abstract}
Pancreatic adenocarcinoma (PDAC) is a disease with a high incidence and a dreary prognosis. Its lack of symptomatology and late diagnosis contribute to the dearth and inefficiency of therapeutic schemes. Studies show that overexpressed epidermal growth factor receptor (EGFR) is a common occurrence, linking this to the progression of pancreatic cancer, although the association between its expression and the survival rate is rather controversial. EGFR-targeted therapy has not shown the results expected, leaving at hand more questions than answers; clearly, there is a need for a better understanding of the molecular pathways involved. Nanoparticles have been used in trying to improve the efficacy of antitumor treatment; thus, using EGFR's ligand, EGF, for nanoconjugation, showed promising results in increasing the cellular uptake mechanisms and apoptosis of the targeted cells.
\end{abstract}

Keywords: pancreatic adenocarcinoma, EGFR, nanoparticles, targeted therapy

\section{Introduction}

Pancreatic cancer is the seventh most frequent cancer in Europe ${ }^{1}$ and the fourth core motive of cancer-associated deaths worldwide. ${ }^{2}$ Despite numerous studies regarding its treatment, it remains a disease with high mortality and morbidity. The standard prognosis for patients diagnosed with pancreatic cancer is very poor, with a median survival of 5-8 months, following the diagnosis. This can be related to the dynamic nature, the prompt appearance of metastasis and the constrained effectiveness of the available treatments. ${ }^{3}$ Only $15-20 \%$ of the patients undergo surgical treatment (pancreatoduodenectomy or Whipple procedure), and merely one in five have long-term survival. ${ }^{4}$

Pancreatic cancer generally affects elderly people, its maximal occurrence being between the ages of 60-80 years. Most of the pancreatic cancers are ductal adenocarcinomas and display a high degree of invasiveness and lack of symptomatology in the initial stages. Regarding the systemic treatment, its efficacy is generally low. The standard treatment in advanced pancreatic cancer is gemcitabine. ${ }^{5}$ A study showed that patients treated with FOLFIRINOX (5-fluorouracil, folinic acid, irinotecan and oxaliplatin) have a higher survival ratio, but it also comes with higher toxicity. ${ }^{6}$

Important pathways related to pancreatic carcinogenesis have been targeted, including the EGFR, amongst others (Ras, VEGF and gastrin). So far, in a Phase 
III trial, erlotinib, an EGFR tyrosine kinase inhibitor, has been proven effective in modestly increasing overall survival, in association with gemcitabine. ${ }^{7}$ Erlotinib was the first targeted therapy approved for pancreatic cancer, although now, its cost-effectiveness is being questioned. ${ }^{8}$

Another recent possibility for first-line treatment in metastatic pancreatic cancer has been approved in 2013: gemcitabine plus albumin-bound nanoparticles - paclitaxel, showing an increase in a survival rate of 1.8 months, its important but treatable side effects including myelosuppression and neuropathy. Three major trials comparing the survival and toxicity of standard treatments in pancreatic cancer (see Table 1) have shown the superiority of FOLFIRINOX in the survival rate. However, as stated before, a higher rate of adverse effects was also reported. Albumin-bound nanoparticles with paclitaxel can be a choice of treatment in patients that cannot endure a more aggressive treatment. ${ }^{9}$

Several studies have demonstrated the implication of EGFR in pancreatic cancer. Its enforced expression is linked to a higher rate of mortality, extensive tumor growth and the appearance of metastasis. ${ }^{12}$ As a result, the EGFR-targeted therapy can be a significant therapeutic strategy in patients with pancreatic adenocarcinoma.
However, most of the EGFR-targeted therapies did not have the expected results, thus, necessitating a better identification of patients eligible for anti-EGFR therapy. ${ }^{13}$ Nanoparticles have proven to be very effective in detection, imaging, targeted therapy and even cancer prevention. Their functionalization with EGF has been shown to be beneficial in augmenting their accumulation in cancer cells, unlike non-functionalized nanoparticles. ${ }^{14}$ Recent research regarding not only the cancer cells, but the tumor microenvironment has pointed out the significant role of pancreatic stellate cells (PaSC) which are found in the tumor stroma (the stroma can represent up to $90 \%$ of the tumor mass). There is strong evidence that the abundance of this type of cells is correlated to the resistance to chemotherapy. ${ }^{15} \mathrm{PaSC}$ are known for generating fibrosis in chronic pancreatitis, and more recently, their role in the production of the extracellular matrix proteins of the tumor stroma was discovered. Therapeutic strategies for targeting the vast stroma are emerging, ${ }^{16}$ thus holding the potential for higher specificity and lower systemic toxicity treatment.

\section{EGFR and Its Role in PDAC}

The epidermal growth factor receptor is a transmembrane glycoprotein belonging to the tyrosine kinase family. In an

Table I Three Major Trials Comparing the Outcomes in Survival and Toxicity of Treatment in Pancreatic Cancer

\begin{tabular}{|c|c|c|c|c|c|c|}
\hline & \multicolumn{2}{|c|}{ Trial I Accord ${ }^{10}$} & \multicolumn{2}{|c|}{ Trial 2 Impact $^{\prime \prime}$} & \multicolumn{2}{|c|}{$\begin{array}{l}\text { Trial } 3 \text { Erlotinib Phase III } \\
\text { Trial }^{32}\end{array}$} \\
\hline & Gemcitabine & FOLFIRNOX & Gemcitabine & $\begin{array}{l}\text { Gemcitabine/ } \\
\text { Nab-Paclitaxel }\end{array}$ & Gemcitabine & $\begin{array}{l}\text { Gemcitabine/ } \\
\text { Erlotinib }\end{array}$ \\
\hline $\begin{array}{l}\text { Median overall survival } \\
\text { (months) }\end{array}$ & 6.8 & II.I & 6.7 & 8.5 & 5.91 & 6.24 \\
\hline $\begin{array}{l}\text { Median progression-free } \\
\text { survival (months) }\end{array}$ & 3.3 & 6.4 & 3.7 & 55 & 3.55 & 3.75 \\
\hline General response rate & $9.4 \%$ & $31.6 \%$ & $7 \%$ & $23 \%$ & $8 \%$ & $8.6 \%$ \\
\hline I-year survival & $20.6 \%$ & $48.4 \%$ & $22 \%$ & $35 \%$ & $17 \%$ & $23 \%$ \\
\hline \multicolumn{7}{|l|}{ Adverse effects } \\
\hline Neutropenia & $21 \%$ & $45.7 \%$ & $27 \%$ & $38 \%$ & - & - \\
\hline Fatigue & $17.8 \%$ & $23.6 \%$ & $7 \%$ & $17 \%$ & $15 \%$ & $15 \%$ \\
\hline Thrombocytopenia & $3.6 \%$ & $9.1 \%$ & $9 \%$ & $13 \%$ & - & - \\
\hline Diarrhea & $1.8 \%$ & $12.7 \%$ & $1 \%$ & $6 \%$ & $2 \%$ & $6 \%$ \\
\hline Infections & - & - & - & - & $17 \%$ & $16 \%$ \\
\hline $\begin{array}{l}\text { Other (febrile neutropenia, } \\
\text { rush, stomatitis) }\end{array}$ & & & $<24 \%$ & $17 \%$ & & \\
\hline
\end{tabular}


ordinary cell, EGFR plays an important role in triggering two main signaling pathways. EGFR is also correlated to multiple cancer-related signaling pathways, playing a part in chemotherapy/radiotherapy resistance, angiogenesis and apoptosis. ${ }^{14}$ In pancreatic ductal carcinoma, EGFR is overexpressed in $30-89 \%$ of the cases. ${ }^{17}$

\section{EGFR Structure}

The glycoprotein EGFR comprises of an extracellular ligand-binding domain, a hydrophobic transmembrane region and a tyrosine kinase cytoplasmic region (Figure 1). The extracellular domain offers a binding point for EGFR's most important ligands - EGF and
TGF- $\alpha$ (transforming growth factor alpha). Their interaction will lead to dimerization and phosphorylation of the cytoplasmic domain, leading to a cascade of subsequent recruitment of signaling molecules. ${ }^{3,18}$ The extracellular domain is itself fractioned into four segments: the first and the third are rich in leucine and play a role in ligand binding, whereas the second and fourth domains are rich in cysteine and take place in the constitution of the disulfide bond. The intracellular domain consists of a juxtamembrane region, a protein kinase domain and a carboxyterminal tail.

The human epidermal growth factor receptor family consists of four types of receptors (HER 1-4); these
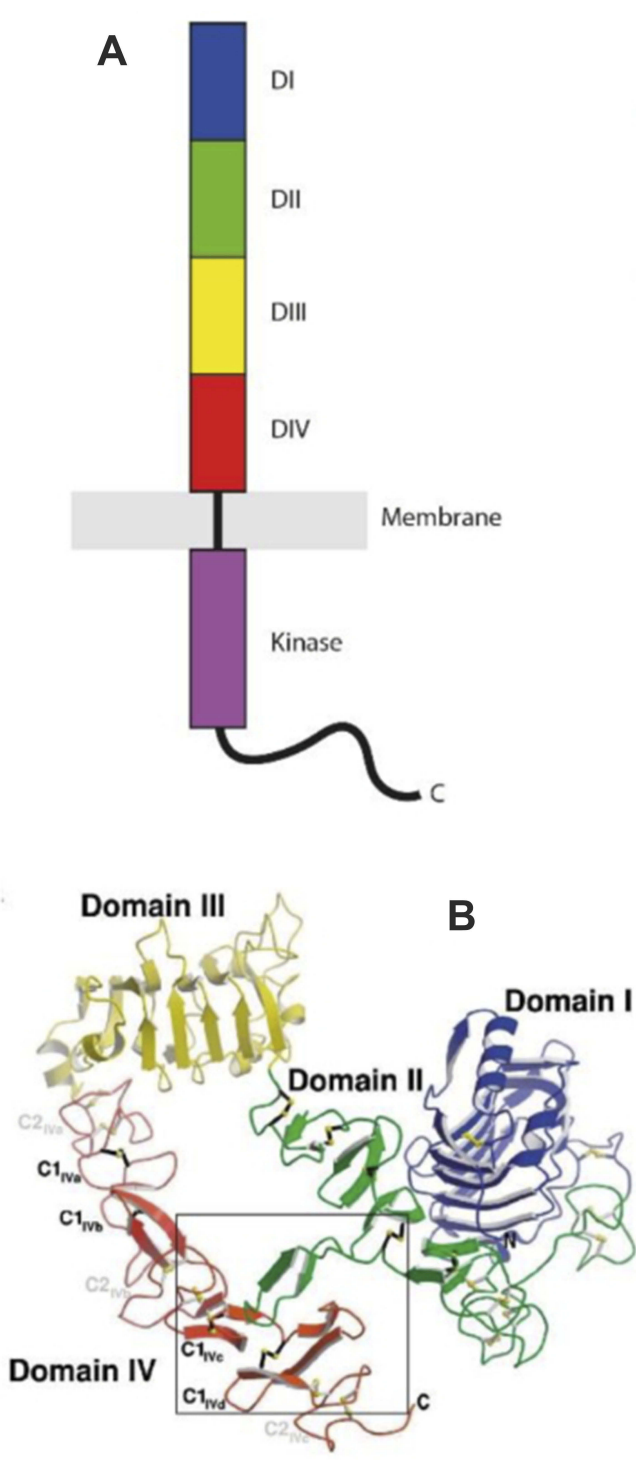
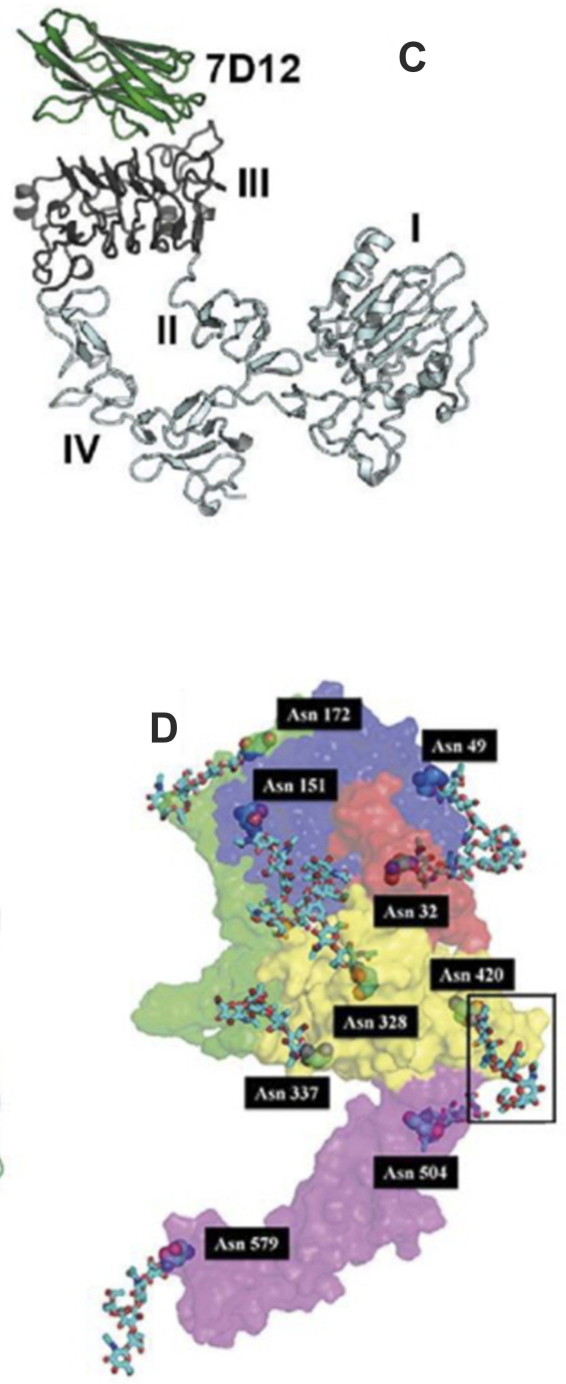
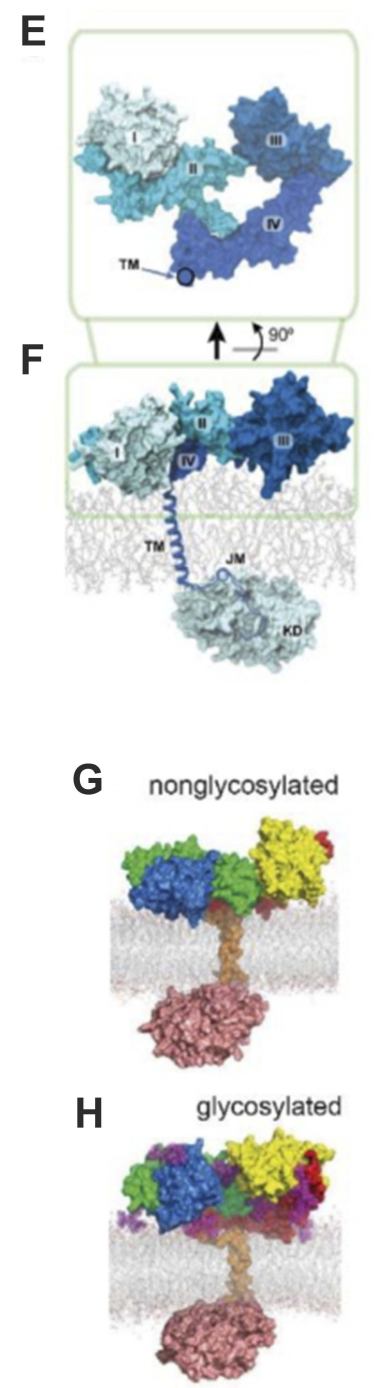

Figure I Structure of EGFR.

Notes: Reproduced with permission from Martin-Fernandez ML, Clarke DT, Roberts SK, Zanetti-Domingues LC, Gervasio FL. Structure and dynamics of the EGF receptor as revealed by experiments and simulations and its relevance to non-small cell lung cancer. Cells. 2019;8(4):316. ${ }^{19}$ 
being included in the ErbB strain of proteins (ErbB 1-4). These receptors are EGFR/ERBB1/HER1, ERBB2/HER2/ NEU (neuregulin), ERBB3/HER3, ERBB4/HER4. The ErbB symbol is derivative from the name of the erythroblastic leukemia viral oncogene, the receptors being homologous to it.

There are seven different types of ligands (growth factors) which bind to EGFR/HER1, none that binds to HER2, two of them that bind to HER3 and seven that bind to HER4. ${ }^{12}$ The receptor ErbB2/HER 2 has no binding domain and ErbB3/HER 3 has no protein kinase domain, and so, they become nonfunctional; ${ }^{7}$ however, there are some studies that indicate a MUC4 mucin that has the ability to regulate and stabilize HER2, therefore maximizing its downstream signaling in pancreatic cancer and ovarian cancer. Given its inability for ligand binding, it is obligatory for HER2 to form a heterodimer with EGFR, HER3 or HER4 to generate high-affinity complexes with different ligands. ${ }^{20,21}$

There are also two different types of juxtamembrane segments (JMa, JMb) and two different types of C-terminal tail (CTa and CTb). Given the different types of ligands that can bind to each of the receptors that can lead to the creation of 28 different combinations of receptor dimers, but, given the fact that ErbB2 and ErbB3 are inefficient, there will be only 26 active dimers. In total, there are 614 combinations of receptors, or 611 active ones, not counting the nonfunctional ErbB2 and ErbB3.

\section{Pancreatic Oncogenesis and EGFR}

In the neoplastic cells, EGFR can be incorrectly activated through numerous mechanisms: ligand-dependent dimerization, point mutations, partial deletions or overexpression. The cascade of pro-oncogenic signaling pathways activated by EGFR begins from the cell membrane and ends in the nucleus. It also plays a part in the induction of cancer-promoting genes, such as cyclin D1 or COX-2,22,23 furthermore, it appears that the EGFR can be expressed in non-neoplastic cells belonging to the tumor microenvironment (TME); here, it plays a part in the stimulation of VEGF, the fibroblast growth factor and interleukin-8, which demonstrate its supportive role in tumor cell proliferation, angiogenesis and metastasis. ${ }^{24}$

Pancreatic ductal adenocarcinoma is a result of several mutations, as seen in Figure 2. The first and most frequent precursor lesion in PDA is the intraepithelial pancreatic neoplasia (PanIN). The progression from PanIN to invasive cancer takes several steps, from PanIN-1 (the events that lead to this stage are most often Kras mutation and shortening of telomers) to PanIN-2 (p16 inactivation is connected with this stage) to PanIN-3 (p53 and SMAD4 inactivation) and finally to invasive carcinoma. ${ }^{25}$ In the progression of PanIN, it is strongly believed that acinar to ductal metaplasia (ADM) is an important precursor. ${ }^{26}$ There are also two other types of non-invasive pancreatic neoplasia: mucinous cystic neoplasm and intraductal mucinous neoplasm.

Genome sequencing has revealed four genes that are most frequently involved in PDAC: Kras, CDKNA2A/p16, SMAD4 and TP53. By far, the Kras oncogene mutations are found in most PDA. Punctiform mutations lead to PanIn formation and then to PDA; however, it seems that Kras is in connection to EGFR activation; without it, the events leading

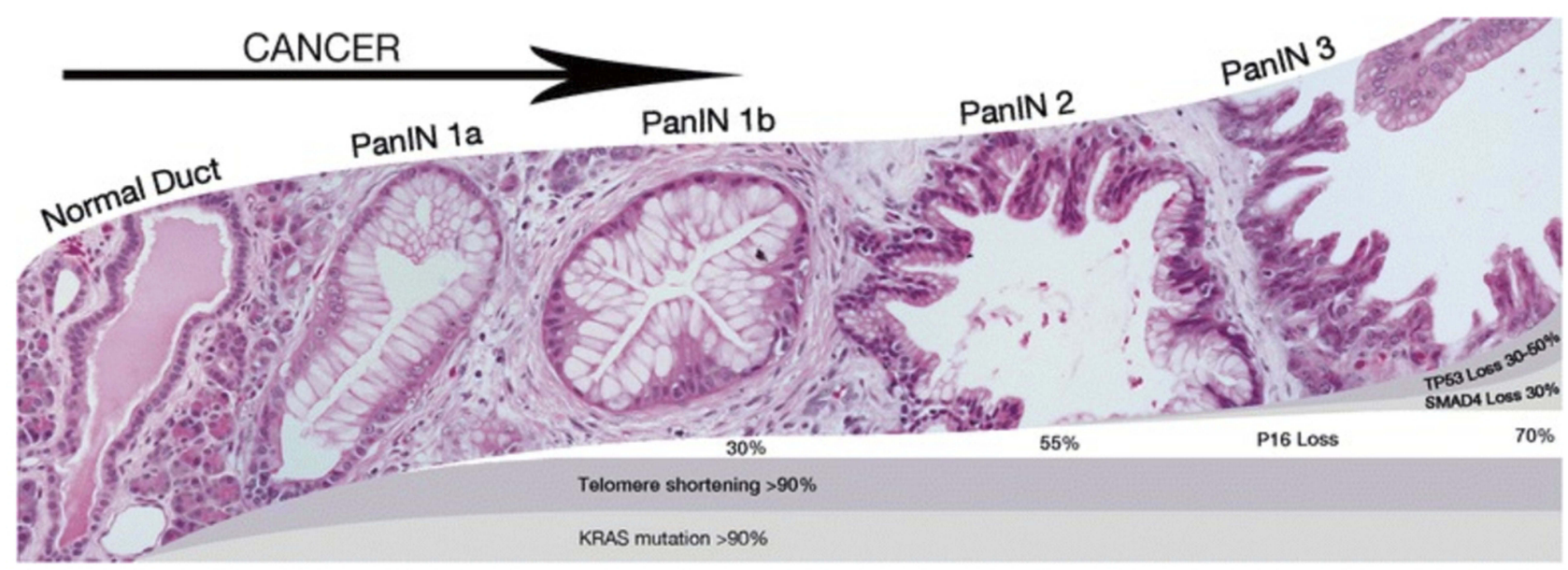

Figure 2 Pancreatic progression from PanIN-I to Panln-3.

Notes: Reproduced with permission from Hackeng WM, Hruban RH, Offerhaus GJA, Brosens LA. Surgical and molecular pathology of pancreatic neoplasms. Diagn Pathol. $2016 ; 11(1): 47 . .^{27}$ 
to epithelial transformation are reduced or absent. The mechanism by which EGFR contributes to Ras mutated PDA is thought to be through the stimulation of complementary oncogenic conduits. ${ }^{25}$ Kras mutations then blocks the capacity of Kras protein to hydrolize guanosine tryphosphate to guanosine dyphosphate, therefore keeping the protein in its active signaling state, to which point it activates other signaling pathways, such as Raf, PI3, with the lack of exogenous growth factors. ${ }^{26}$

\section{EGFR Mutations}

It has been proven that increased expression of EGFR is linked to structural or numerical alterations of chromosome 7, as the EGFR gene has been mapped to its short arm (7p). The c-ERBB-1 proto-oncogene is the one that encodes EGFR. In a normal pancreas, c-ERBB-1 is expressed only in the islets of Langerhans, but in human pancreatic cancer cell lines, it is overexpressed in up to $85 \%$ of ductal adenocarcinomas. ${ }^{28}$ Tzeng et al analyzed EGFR mutation in pancreatic cancer cell lines and found that $81 \%$ were silent mutations, concluding that it is unhelpful to be used as a predictor for the response to antiEGFR therapy as it is in NSCLC. ${ }^{29}$

\section{Involvement of EGFR in the Progression and Prognosis of PDAC}

There are many studies that relate to the presence of overexpressed EGF receptors and poor prognosis in patients diagnosed with pancreatic cancer. Valsecchi et al tested 105 patients diagnosed with PDA and found that EGFR was overexpressed in $30.4 \%$ of cases, and these patients were are found to also have lymph node metastasis $(\mathrm{P}=0.038)$ and generally shorter survival rates. They concluded that EGFR is an important predictive factor. ${ }^{30}$ Another study that analyzed 76 tissue samples from patients with PDA, comparing the invasive and intraductal components, demonstrated a cytoplasmic overexpression of EGFR, being more recurrent in invasive components $(62 \%)$, compared with the intraductal ones. These findings implied a correlation between the overexpression of EGF and the higher rate of evolution for pancreatic cancer but found no evidence of this phenomenon being related to a lower survival rate.

There are some immunohistochemical studies that proved the implication of EGFR in the progression of pancreatic cancer. It was found that EGFR was overexpressed in over $80 \%$ of PanIN1a lesions and frequently overexpressed in ADM, leading to the conclusion that the activation of EGFR signaling pathway is an early event. Two other studies performed on genetically engineered mouse models of pancreatic cancer showed that EGFR was required in ADM formation. ${ }^{26}$

\section{EGFR-Targeted Therapy}

Inhibition strategies for blocking the signaling pathways activated during EGFR expression include using monoclonal antibodies - these have the potential to bind to the extracellular binding site of EGFR and, therefore, specifically inhibit ligand binding, preventing further receptor dimerization and downstream signaling. The advantages of using monoclonal antibodies include their specificity, their predictability in pharmacokinetics, the fact that their serum half-lives are quite long, all resulting in the possibility of fewer doses needed by the patient. Cetuximab as a monoclonal antibody appeared to be well tolerated, both alone and in combination with radiotherapy. Its adverse effects include nausea, weight loss, rash, asthenia and abdominal pain. But Phase III studies did not confirm the advantages found in preclinical studies, and they concluded that treatment with cetuximab does not improve patient outcomes. $^{31}$

Another strategy for targeting EGFR is using tyrosine kinase inhibitors (TKIs). They represent a class of lowweight molecules that compete with the adenosine triphosphate (ATP) for binding to the kinase domain of EGFR, subsequently, stopping the downstream signaling process. Erlotinib as a TKI is one of the main drugs in this class, together with gefitinib. A Phase III study for erlotinib and gemcitabine was the first FDA-approved combination therapy in the treatment of unresectable pancreatic cancer - it showed improved although modest overall survival -6.4 months for combination therapy compared to 5.9 months for the control group. Important adverse effects include rash, diarrhea, infection and stomatitis. Erlotinib is also currently evaluated in combination with capecitabine, for patients who do not respond to first-line combined treatment. ${ }^{32}$

EGFR targeted agents in combination with radiotherapy there are several studies that implicate that there is a connection between the EGFR expression and cellular resistance to radiation: the higher the overexpression, the bigger the degree of radioresistance; as a result, the necessity to associate an EGFR targeting molecule to radiotherapy has emerged. Cetuximab, for example, in combination with radiotherapy, showed promising results with little to no additional toxicity, but this study has not yet progressed to Phase III trials. ${ }^{33}$

Nanoparticles targeting EGFR can be conjugated directly with antibodies (such as gemcitabine, paclitaxel, doxorubicin); 
such nanoparticles include liposomes, polymeric nanoparticles, carbon nano-diamonds, gold nanoparticles and others. They can also be conjugated with antibody fragments; it is known that antibodies consist of distinct regions, but some fragments are of higher importance than others for receptor binding. Manot et al delivered modified cetuximab fragments conjugated to liposomes to glioma and epidermoid carcinoma cells and achieved $80 \%$ cell death in vitro. ${ }^{34}$

\section{EGF Binding to EGFR and the Pathways Involved in PDAC}

Stanley Cohen, the author of Nobel prize-winning studies, was the one who delivered groundbreaking work for the EGFR field in 1959. He reached the conclusion that murine EGF was responsible for augmenting DNA synthesis in human cultured fibroblasts. He proceeded to demonstrate that EGF could bind the EGFR protein, resulting in its phosphorylation. EGFR was also the first demarcated tyrosine kinase receptor. ${ }^{35}$ Human EGF is a $6-\mathrm{kDa}$ protein composed of 53 amino acids. It is mainly concentrated in bile, prostate fluid, urine and milk. ${ }^{36}$ The EGF is associated with the morphogenesis of the reproductive tracts, the teeth, the brain and with epithelial regeneration. ${ }^{37}$ EGF is considered to be one of the most significant ligands out of all the ligands that have the ability to bind to EGFR. Each of them, however, appears to activate EGFR in the same manner. ${ }^{38}$

Activation of EGFR signaling can be triggered by ligandinduced receptor dimerization, when the tyrosine residues found in the intrinsic domain of one of the receptors cross phosphorylate specific residues in the C-terminal tail of the partnering receptor, all this leading to the recruitment of effector proteins. This will eventually activate the signaling cascades. $^{39,40}$ The two signaling pathways activated by EGFR are (1) the rat sarcoma/recombinant activated factor/ mitogen-activated protein kinase (MAPK) extracellular signalregulated kinase/MAPKs (RAS/RAF/MEK/MAPK) pathway, which is involved in cell proliferation, gene transcription and the cell cycle progression. The second pathway is the phosphatidylinositol-3 kinase (PI3K)/Akt which plays a role in activating a cascade of anti-apoptotic and pro-survival signals. All these signaling processes are often deregulated in malignant cells because of several mutations of various genes involved in the pathways. ${ }^{22}$

Two EGF ligands bind to the extracellular domain of two EGFR monomers, this process then conducting to the development of a dimer. When this conformational change occurs, the carboxyl terminal end of one tyrosine kinase domain moves into the active site of the opposing tyrosine kinase domain; this process allows the phosphorylation of various tyrosine residues on the C-terminal tail. Some of these residues bind to GRB2 (growth factor receptor-binding protein 2), which links the activated EGFR to intricate biochemical interactions. GRB2 acts like an adaptor protein, it does not activate any processes, but is an anchor for the SOS protein. SOS contains an active site that binds Ras protein. ${ }^{41}$ The ras protein can be found in an active and inactive state; in its active state it allows the binding of GTP molecules and while inactive GDP molecules. K-ras mutations, which are found in almost $90 \%$ of pancreatic cancers, lead to ras being permanently active, hence, being able to activate intracellular signaling even with the lack of outside stimulus. Ras will expel a GDP protein and bind a GTP, the activated protein then moving to activate a protein kinase called Raf. Ras itself does not actually activate Raf, but it inducts Raf activation by moving it to the plasma membrane, where supplementary processes take place. ${ }^{42,43}$ Raf will eventually lead to activation of protein kinases called MEKs - MEK1 and MEK2, the only known substrates, which have the ability to move into the nucleus and stimulate transcription factors to increase gene expression. ${ }^{44}$

The second and equally important signaling pathway activated by EGF binding to EGFR is the PI3K-AKT-mTOR (mammalian target of rapamycin). It plays an important role in proliferation, endurance and motility, cell dimensions and metabolism. ${ }^{45} \mathrm{PI} 3 \mathrm{~K}$ is activated by EGF stimulation. ${ }^{46}$ After activation, it converts PIP2 (phosphatidylinositol-4,5-bisphosphate) into PIP3 (phosphatidylinositol-3,4,5-triphosphate). PIP3 then recruits AKT, or protein kinase $\mathrm{B}$, which is a kinase that includes three family members - AKT 1, AKT 2 and AKT 3. AKT 2 appears to be overexpressed in pancreatic cancer. ${ }^{47}$ Once activated, it leads to a series of other processes, one of the most importance being the signaling to mTOR, which plays an important role in cell evolution and autophagy. ${ }^{48}$ This pathway seems to also be involved in the control of cell metabolism and glycolysis in cancer.

\section{Nanoparticles in Cancer}

Nanotechnology compiles the studying of matter that involves dimensions of 1 to $100 \mathrm{~nm}$. A nanoparticle being quantified on a nanoscale represents the billionth part of a meter. ${ }^{13,49}$ Nanomaterials are largely studied for their numerous advantages: their structure can be modified to target a specific tissue, to be gradually and controllably released, and given the fact that they are smaller than human cells, they can easily interact with DNA ( $2 \mathrm{~nm}$ diameter), viruses (20 nm diameter), cell surface receptors $\left(10 \mathrm{~nm}\right.$ diameter). ${ }^{49}$ 
Neoplastic tissues are compartmentalized into three distinct divisions: the cellular, the interstitial and the vascular one. Regarding tumor blood vessels, their unique proprieties, such as a high concentration of endothelial cells, a low concentration of pericytes and an abnormal formation of the basement membrane, contribute to the supply of nutrients and oxygenation much needed by the cancer cells for survival. Their distribution is heterogeneous, and some regions of the tumor can be very well vascularized, while other regions can lack blood vessels. The pre cutoff size is between 380 and $780 \mathrm{~nm}^{50}$

The interstitial compartment is basically composed of collagen and elastic fibers. Unlike normal tissues, its high interstitial pressure leads to outward interstitial fluid flow; it also lacks the anatomically and correct functioning lymphatic network. $^{51}$

Given all this, the delivery of anticancer drugs to neoplastic tissue must defeat several barriers, such as a) drug resistance at tumor level caused by physiological barriers - this could be caused by the lack of vascularization, leading to reduced drug access; also, the high interstitial pressure or low microvascular pressure may interfere with the delivery of the drug; b) drug resistance at a cellular level - such as defect apoptosis regulation, multidrug resistance (MDR) caused by the P-glycoprotein efflux system or MRP - multidrug resistance-associated protein; c) distribution and elimination of therapeutic agents in the body - because of their large volume of distribution, anticancer drugs are often toxic to both tumor and normal cells, limiting the efficacy of the treatment. In the light of these discoveries, the need for something else has emerged. ${ }^{49}$

Nanoparticles have shown great value in early detection, imaging, targeted therapy and even prevention of cancer. ${ }^{13,49}$ In comparison to conventional chemotherapy agents, nanocarriers can be actively and passively aimed at particular cells and circumvent from being toxic to normal cells. $^{49}$ But, despite their distinctive proprieties which allow them to be used in targeted therapy, their capability to release their load into the selected cells and the cell intake mechanism has been questioned; therefore, the need to attach the nanoparticles to ligands, to elevate their cell absorption, has appeared. These ligands increase the nanoparticles' chances to be recognized by cell receptors. ${ }^{14}$ Also, to maximize their efficacy, they can be functionalized with polyethyleneglycol (PEG), which has proven potent in avoiding the destruction of nanoparticles by the reticuloendothelial system. ${ }^{52}$ Some types of nanoparticles have even proven to be able to avoid MDR resistance.

There are many types of nanoparticles (Figure 3) used for specific drug delivery, such as polymeric nanoparticles,

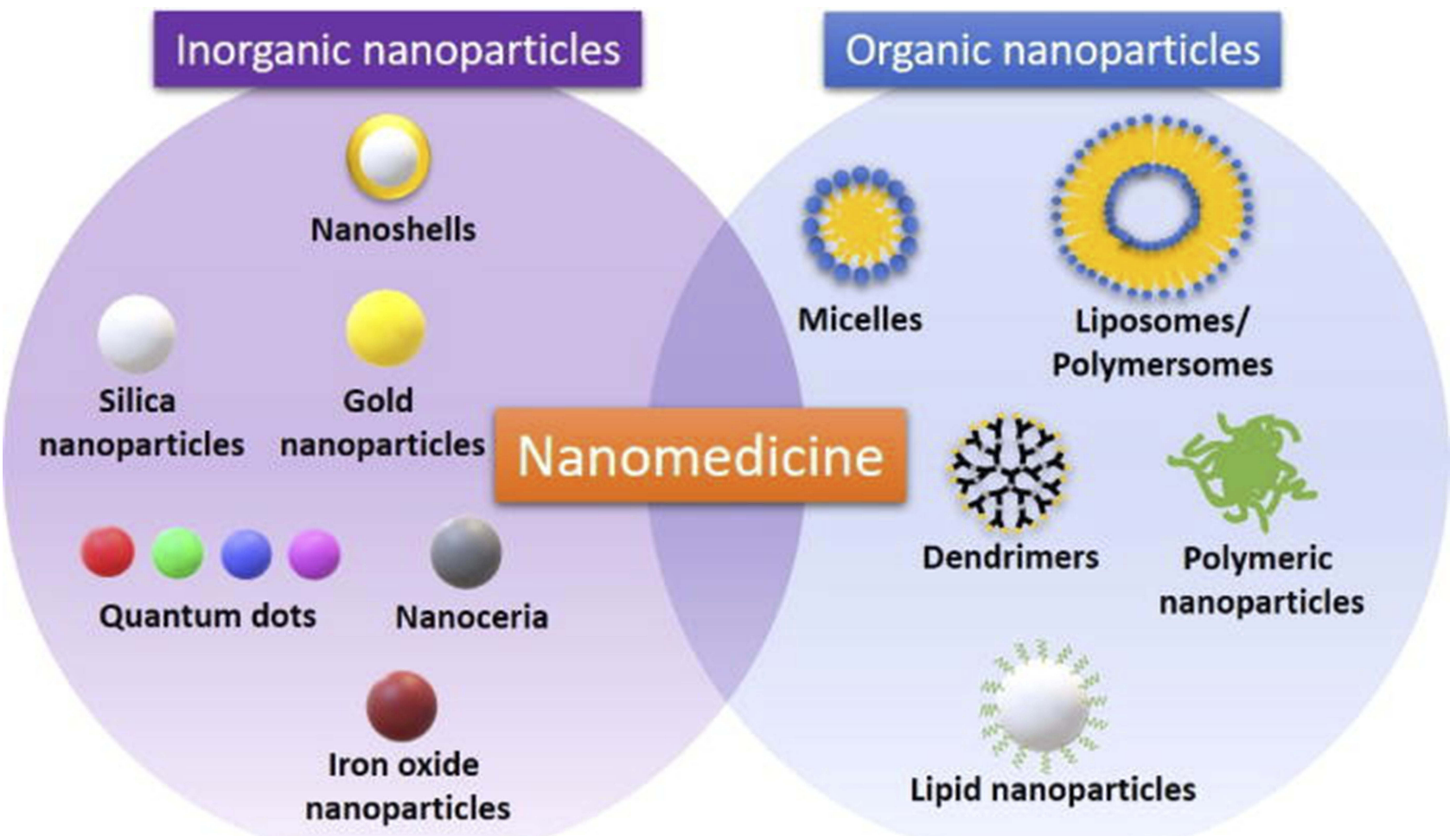

Figure 3 Classes of inorganic and organic nanoparticles used in diagnosis and treatment of cancer (teranostics).

Notes: Reproduced with permission from Martinelli C, Pucci C, Ciofani G. Nanostructured carriers as innovative tools for cancer diagnosis and therapy. APL Bioeng. 20I9;3(I):0I I502. ${ }^{54}$ 
polymeric micelles, dendrimers, liposomes, viral nanoparticles and carbon nanotubes. ${ }^{53}$

\section{Surface Nanofunctionalization of Nanoparticles}

Using an array of methods, nanoparticles have been functionalized with different ligands, such as polymers, biomolecules, surfactants or dendrimers (see Table 2). And, although this process holds promise for a better drug delivery system, certain aspects are very important for the process to be successful, the cellular uptake mechanism of a functionalized nanoparticle being the most important one. Also, functionalized nanoparticles should be non-cytotoxic, stable, and have specificity for the targeted tissue or cell. ${ }^{55}$ The first step of the interaction of the functionalized nanoparticle with the cell is the adsorption on the cellular surface, followed by the uptake. There are different cellular uptake pathways, the most common one being endocytosis. It is important to know that the process of uptake is influenced by both external factors (temperature, $\mathrm{pH}$, concentration) and the nanoparticle's surface proprieties (size, shape, surface modifications). The cellular uptake of nanoparticles with specific binding ligands is generally better. ${ }^{56}$

Table 2 Up-to-Date Models for Nanostructures Designed and Tested for Efficient PC Therapy

\begin{tabular}{|c|c|c|c|}
\hline $\begin{array}{l}\text { Type of Nano- } \\
\text { System }\end{array}$ & Name of Nano-System & Drug Formulated & Testing Phase \\
\hline \multirow[t]{4}{*}{ Polymer-drug } & Poly(ethylene glycol)-P(HEMASN38) & SN3S & Preclinical: in vivo \\
\hline & Poly (TPGS)-PEG-GEM & Gemcitabine & Preclinical: in vitro \\
\hline & Methacrylate-based GEM-monomer conjugate 3 & Gemcitabine & Preclinical: in vitro \\
\hline & $\begin{array}{l}\text { Poly (ethylene glycol)-block-poly ( } 2 \text { methyl-2- carboxyl- } \\
\text { propylene carbonate)-graft-dodecanol-graft-cationic ligand }\end{array}$ & Gemcitabine & Preclinical: in vivo \\
\hline \multirow[t]{2}{*}{ Block copolymer } & Styrene-maleic acid & CDF & Preclinical: in vivo \\
\hline & Poly(ethylene glycol)-b-poly(glutamic acid) & Oxaliplatin & Preclinical: in vivo \\
\hline Mixed micelles & $\begin{array}{l}\text { Poly(vinyl pyrrolidone-b-polycaprolactone) (PVP- } b-\mathrm{PCL}) \text { and } \\
\text { poly(vinyl pyrrolidone-b- poly(dioxanone-co-methyl } \\
\text { dioxanone)) (PVP-b- P(DX-co-MeDX) }\end{array}$ & $\begin{array}{l}\text { Gemcitabine, doxorubicin. } \\
\text { Doxorubicin hydrochloride. 5- } \\
\text { fluorouracil paclitaxel }\end{array}$ & Preclinical: in vitro \\
\hline Graft polymer & Poly(allylamine)-g-cholesterol & BNIPDAoct & Preclinical: in vivo \\
\hline \multirow[t]{2}{*}{ Dendrimer } & PAMAM-hyaluronic acid & CDF & Preclinical: in vitro \\
\hline & Poly(ethylene glycol)-PMAM-poly(ethylene glycol)-Flt-2 & Gemcitabine Hydrochloride & Preclinical: in vitro \\
\hline $\begin{array}{l}\text { Thermo-responsive } \\
\text { polymer }\end{array}$ & Poly(diEGMAco-OEGMA300)-b-PEHMA & Squalenoyl-gemcitabine & Preclinical: in vitro \\
\hline $\begin{array}{l}\text { pH-responsive } \\
\text { polymer }\end{array}$ & Poly(styrene-alt-maleic anhydride) & Curcumin & Preclinical: in vitro \\
\hline $\begin{array}{l}\text { Ultrasound-responsive } \\
\text { nano-emulsion }\end{array}$ & PEG-PLLA & Paclitaxel & Preclinical: In vivo \\
\hline \multirow[t]{2}{*}{ Albumin } & Abraxane $^{\circledR}$ & Paclitaxel & $\begin{array}{l}\text { FDA approved } \\
2013\end{array}$ \\
\hline & Abraxane ${ }^{\circledR} /$ Gemcitabine & Paclitaxel \& gemcitabine & Phase III \\
\hline \multirow[t]{4}{*}{ Inorganic nanoparticle } & Iron oxide-dextran-DOX & Doxorubicin & Preclinical: in vitro \\
\hline & Iron oxide-antiCD47-GEM & Gemcitabine & Preclinical: in vitro \\
\hline & Iron oxide-gold & BNIPDSpm & Preclinical: in vivo \\
\hline & Iron oxide-gold-GEM & Gemcitabine & Preclinical: in vivo \\
\hline
\end{tabular}

Notes: Reprinted with permission from Manzur A, Oluwasanmi A, Moss D, Curtis A, Hoskins C. Nanotechnologies in pancreatic cancer therapy. Pharmaceutics. 2017;9(4):39.76 


\section{EGF Functionalized Nanoparticles - Results So Far}

Nanoparticles can also be conjugated using EGFR's own ligand, EGF. EGF is a protein composed of 53 amino acids, and it has three SS bonds and numerous hydrophobic residues, all suitable for interactions with nanoparticles. ${ }^{57}$ Its advantages include its small size compared to antibodies or even antibodies fragments, its specificity being the native ligand and the fact that antibodies are more prone to triggering severe immune responses, therefore causing higher cytotoxicity. Unfortunately, its use has also disadvantages, such as EGF is less available from human resources, it is expensive, difficult to obtain, and the one from murine sources causes antigenicity issues. ${ }^{58}$ Studies so far show promising results.

The first in vivo targeted killing of squamous carcinoma cells that overexpressed EGF receptors was done by Bhirde et al, when they functionalized a single-wall carbon nanotube with EGF and cisplatin (See Figure 4). The results of the functionalized carbon nanotubes were superior compared to the non-targeted bioconjugates. ${ }^{59}$ Tseng et al used gelatin nanoparticles functionalized with biotinylated EGF for evaluation of the distribution and aiming ability via aerosol distribution in lung cancer cells in mice. The study concluded that there was a significant
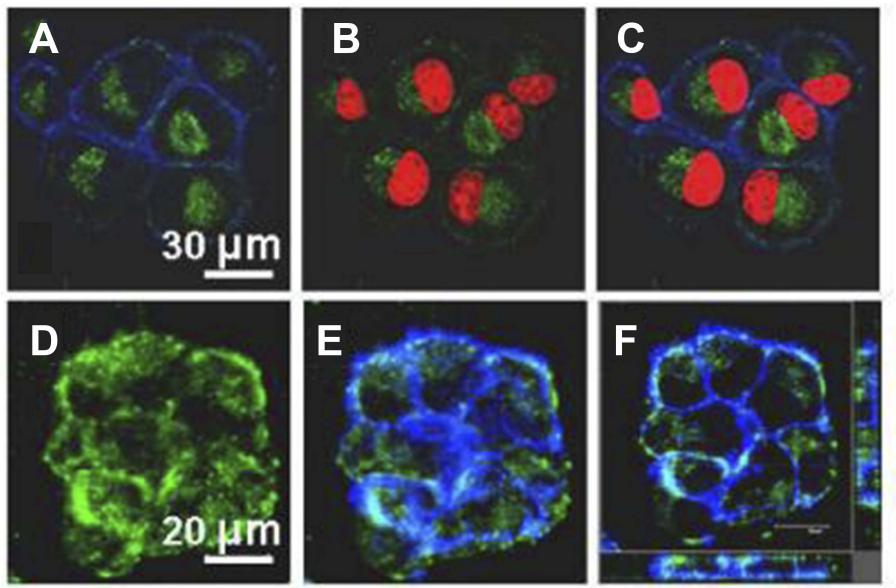

G

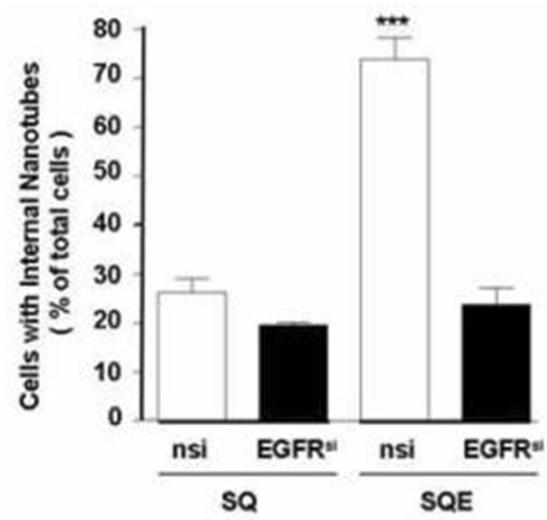

non silencing $R N A=n s i$; $E G F R$ siRNA = EGFR

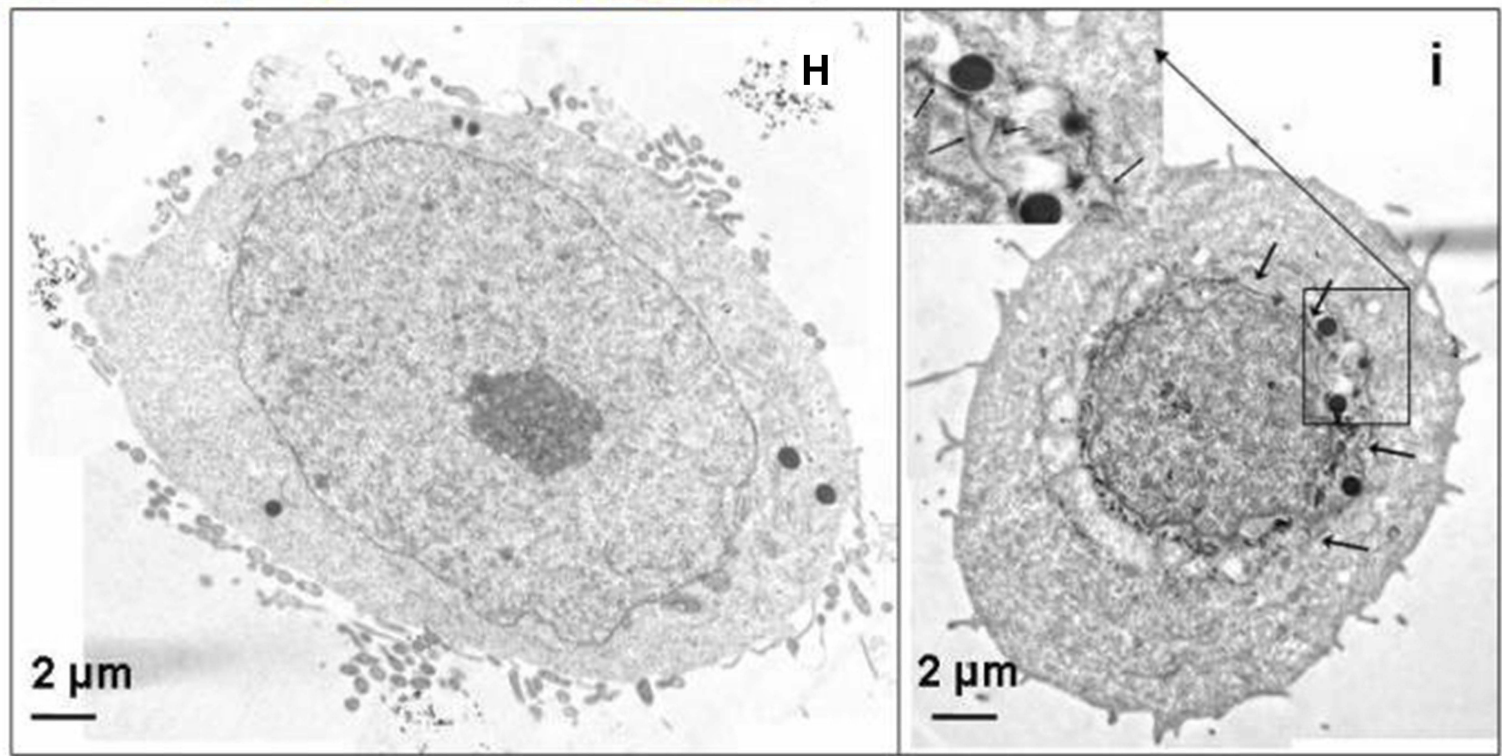

Figure 4 In vitro experiment demonstrating antitumor targeted effects of carbon nanotubes functionalized with EGF and cisplatin. (A-C) Confocal microscopy showing the cellular internalization of SWNT-Qdot525-EGF (SQE) nanoconjugates; the green fluorescence of Qdot525 indicates the intracellular localization of the bioconjugate (the nuclei are red). (D-F) 3D reconstructions that confirm the localization of quantum dots that are green. (G) Shows how higher levels of EGFR expression determine a higher cellular uptake of the bioconjugate. Treatment with siRNA was used for blocking EGFR. Differences between control/SQE and the other samples were significant, $\mathrm{P}<0.05$. $(* * *)$. (H) and (I) Transmission electron microscopy images that show cells exposed only to SWNT-Qdot without EGF; (H) - there is no trace of nanoparticles being internalized and cells exposed to SQE (I) - the arrows indicate the presence of nanoparticles in the perinuclear region. Reprinted with permission from Bhirde AA, Patel V, Gavard J, et al Targeted killing of cancer cells in vivo and in vitro with EGF-directed carbon nanotube-based drug delivery. ACS nano. 2009;3(2):307-316. Copyright (2009) American Chemical Society. ${ }^{63}$ 
accumulation of EGF functionalized nanoparticles in tumor-bearing mice, compared to normal mice. The inflammatory response in the lungs was also taken into consideration, and it appears that not only the level of myeloperoxidase did not rise, but its activity was actually diminished in mice treated with EGF gelatin nanoparticles. The internalization of EGF was also faster than other antiEGFR antibodies in EGFR overexpressing cells. ${ }^{60}$ Shimada et al evaluated the cytotoxicity and tumor inhibition of paclitaxel integrated into EGF-conjugated polymeric lipid-based nanoparticles in mice overexpressing EGFR. He concluded that even though there is a significant decrease in tumor growth and greater toxicity in vivo and in vitro, in time, tumor size still increased compared to control groups. ${ }^{61}$ Sandoval et al demonstrated that murine EGF-conjugated lipid nanoparticles led to an indicative decrease in tumor volume in vivo. ${ }^{62}$ In one study, Sang et al radiolabeled EGF gold nanoparticles with indium to target EGFR expressing breast cancer cells. The study showed that functionalization with EGF of gold nanoparticles and radiolabelling did not interfere with an affinity for EGFR and also showed greater radiotoxicity, which can be beneficial for targeted radiotherapy. ${ }^{63}$ In another study, superparamagnetic iron oxide nanoparticles were conjugated with EGF (SPIONEGF) for the specific targeting of glioma cells. They were used as a potential agent for contrast augmentation in magnetic resonance imaging on a glioma cell culture. The study concluded that SPION-EGF could heighten the contrast for imaging in gliomas that overexpressed EGFR and could also be used for targeted delivery. ${ }^{64}$

Creixell et al used EGF-conjugated iron oxide magnetic nanoparticles to demonstrate their increased accumulation into colon cancer cells that overexpressed EGFR compared to unfunctionalized nanoparticles after $1 \mathrm{hr}$ of incubation. The internalization of nanoparticles was visualized using confocal microscopy, proving that the functionalized nanoparticles can be taken up by both receptor-mediated endocytosis mechanism and also receptor-independent mechanism. ${ }^{65}$ A study of 3 pancreatic cancer cell lines overexpressing EGFR in different proportions demonstrated that after the administration of EGFconjugated liposomes containing curcumin, the antitumor activity of curcumin was amplified. The explanation lies in the fact that the cells that overexpressed the largest amount of EGFR were those that accumulated most of the functionalized nanoparticles, and, as a consequence, facilitating curcumin transfer into cancer cells, and achieving greater cytotoxicity. ${ }^{66}$ EGF-functionalized gold nanoparticles have been used in a study on multiple cell lines - breast, colon, lung, prostate and cervical cancer, and then subjected to nonthermal atmospheric pressure plasma (NTP) therapy. It was concluded that pre-administration of the conjugated nanoparticles resulted in substantial improvement in NTP treatment, the nanoparticles being internalized by receptor-mediated endocytosis, and subsequently leading to a selective increase in cellular apoptosis. ${ }^{67}$ Relying on the benefits of using the EGF molecule (small size, stability under physiological conditions, high-temperature denaturation, over $76^{\circ} \mathrm{C}$ ), it was also concluded that EGF-functionalized gold nanoparticles may yield promising results in photothermal therapy of cancer. ${ }^{68}$

A 2011 study has tested the cytotoxicity of single-wall carbon nanotubes (SWCNT) functionalized with EGF in a pancreatic adenocarcinoma cell line (Panc-1). This was assessed by measuring the LDH level and the metabolic function of the treated cancer cells, and the results showed that SWCNT-EGF was less toxic at higher doses, concluding that EGF improves biocompatibility. Also, through Raman spectroscopy, intense accumulation of SWCNT-EGF was seen around the cell membrane and within cells, proportional to the incubation time. The ELISA technique was used to analyze the process of association/dissociation of the EGF molecule from the cell, demonstrating that the presence of EGF is essential for cellular SWCNT delivery, and that the process of association/dissociation, being balanced, allows accumulation of a substantial amount of nanotubes in the vicinity of the cell membrane. These findings are conducive for achieving the ultimate goal of these types of studies, namely, to deliver a sufficient amount of nanomaterial in order to produce the complete thermal ablation of cancer cells. ${ }^{69}$

Despite extensive research on ligand nanoconjugation, the impact of this process on cellular uptake, intracellular transport, and the way these changes have repercussions on intracellular signaling pathways and the therapeutic effect are not yet fully elucidated. Nanoconjugation with EGF can induce apoptosis, ${ }^{69,70}$ but the mechanisms behind this process are still unclear. For gold nanoparticles, free oxygen radicals (ROS) are generated due to mitochondrial damage that will lead to apoptosis. ${ }^{71}$ The induction of this process is essential in the treatment of cancer, as tumor cells have effective mechanisms to bypass it. In a recent study, both the cytoplasmic ROS level and the mitochondrial superoxide level after the addition of EGF-conjugated gold nanoparticles were measured. It was found that the level of cytoplasmic ROS increased after the administration of 
conjugated nanoparticles, but the level of mitochondrial superoxide remained unchanged; there was also no decrease in the mitochondrial membrane potential. In addition, it has been demonstrated that EGF density, nanoparticle shape and size contribute to influencing the effectiveness of apoptosis: an increased density of EGF, spherical shape and size over $80 \mathrm{~nm}$ favor apoptosis. ${ }^{72}$ Given all this, the importance to characterize the response to the conjugated nanoparticles in order to determine the doses needed to amplify the antineoplastic potential is highlighted.

In addition to activating cell signaling pathways, EGFEGFR coupling will also lead to the internalization of the ligand-receptor complex by endocytosis. In cells that physiologically express EGFR, claritin-dependent endocytosis is activated, whereas in cells overexpressing EGFR, endocytosis is produced by claritin-independent mechanism. The complex migrates from the early endosomes to the late ones, then to the lysosomes and finally, they are degraded. ${ }^{73}$ It is important to note that even after internalization in endosomes, the phosphorylated tyrosine kinase domain remains exposed in the cytoplasm, continuing the cell signaling process until the time of dephosphorylation. It is also established that in some cell lines that overexpress EGFR, EGF has the ability to induce cellular apoptosis. It has been observed that apoptosis can be induced by exposing epidermoid carcinoma cell lines (A431) or breast cancer (MDA-MB-468) cell lines to free EGF, the EGF-EGFR complex being retained for a long time in the early endosomes. Inhibition of endocytosis will also reduce the efficiency of signaling by MAPK and PI3K. ${ }^{74}$ Based on this premise, the administration of EGF-functionalized gold nanoparticles on MDA-MB-468 cultures was attempted; the conjugated nanoparticles were retained in early endosomes for a longer time at much lower EGF concentrations compared to free EGF needed to induce apoptosis. ${ }^{75}$

\section{Nanotechnology in Pancreatic Cancer}

Besides conjugation with EGF, other types of ligands with different types of nanoparticles were used so far including dendrimers, polymers, albumin and inorganic particles, which have been bound to different chemotherapeutics, with promising results. ${ }^{76}$ Their final aim is to develop a combination that can surpass the dense stroma in pancreatic cancer, with a good uptake and specificity for this type of cancer. Poly (ethylene glycol)-P(HEMASN38) and SN38 (the active metabolite of irinotecan) showed an increase in the level of apoptosis, a reduction in the level of collagen and overall favorable efficacy in the treatment of pancreatic cancer cells. ${ }^{77}$ SPION and doxorubicin directed to pancreatic cancer cells have successfully demonstrated an increase in drug internalization - despite not using a ligand, doxorubicin accumulated in the cell nucleus at a higher level compared to using the chemotherapeutic alone, and this result proves that it may be possible to administer even basic drugs with the help of nanotechnology. ${ }^{78} \mathrm{~A}$ thermo-triggered polymer and Squalenoyl-Gemcitabine - Paclitaxel were effectively used in trying to improve drug uptake and promoting cellular destruction. ${ }^{79}$ A recent in vivo study of hybrid iron oxidegold nanoparticles (HNPs) and bisnaphthalimide drug equivalents delivered good results: they tested reversible binding of the compound, showing that the drugs could be released at degrees of over $44{ }^{\circ} \mathrm{C}$ offering an alternative thermal treatment in this type of cancer. ${ }^{80}$ Gemcitabine was also used in combination with HNPs in the hope of improving gemcitabine uptake in vivo. Gemcitabine was successfully released, the process being heat triggered, and the cell viability decreased by $26 \%{ }^{81}$ Liposomal irinotecan was approved in 2016 for treatment in patients with advanced pancreatic cancer; however this treatment also came with dangerous toxicity, and its use is now being questioned. In the hope of reducing toxicity and because the liposomal carrier used for delivery of irinotecan has not shown the results expected, a study used silica nanoparticles and irinotecan and proved better accumulation of the compound, a superior therapeutic effectiveness and a reduced amount of systemic outflow compared to the liposomal transporter. ${ }^{82}$

Other studies involving nanocarriers used for treatment in pancreatic cell lines have shown encouraging results. Each study comes with its own set of improvements and setbacks, and there are clearly a variety of modulatory factors for treatment efficiency.

\section{Conclusions}

It is becoming more and more clear that the complexity of EGFR signaling and expression in pancreatic cancer is a promising field of study for developing new and improved strategies of treatment. It is also important to find ways of identifying those patients who would benefit the most from EGFR-targeted therapy.

Even though nanoconjugation has been proven effective in drug delivery to various types of cancer, pancreatic adenocarcinoma is a particularly dense tumor, making the quest for finding the best way to deliver treatment challenging. 
Following studies on EGF-conjugated nanoparticles, it can be deduced that, in general, bioconjugation amplifies the apoptotic effect and the already existing nanoparticle toxicity due to their structure. Also, EGF-conjugated nanoparticles may be beneficial not only in the treatment of overexpressing EGFR cancers but also in their imaging. However, it is imperative to characterize the mechanisms underlying these processes, their understanding being an essential factor in determining the doses needed to amplify the antineoplastic potential.

\section{Acknowledgements}

This work was supported by the Romanian National Authority for Scientific Research and Innovation, CNCSUEFISCDI, project number PN-III-P1-1.1-TE-2016-2161.

\section{Disclosure}

The authors report no conflicts of interest in this work.

\section{References}

1. Seufferlein T, Bachet J, Van Cutsem E, Rougier P; ESMO Guidelines Working Group. Pancreatic adenocarcinoma: ESMO-ESDO clinical practice guidelines for diagnosis, treatment and follow-up. Ann Oncol. 2012;23(suppl_7):vii33-vii40.

2. Oliveira-Cunha M, Newman WG, Siriwardena AK. Epidermal growth factor receptor in pancreatic cancer. Cancers. 2011;3 (2):1513-1526. doi:10.3390/cancers3021513

3. Vaccaro V, Melisi D, Bria E, et al. Emerging pathways and future targets for the molecular therapy of pancreatic cancer. Expert Opin Ther Targets. 2011;15(10):1183-1196. doi:10.1517/14728222.2011.607438

4. Gillen S, Schuster T, Zum Büschenfelde CM, Friess H, Kleeff J. Preoperative/neoadjuvant therapy in pancreatic cancer: a systematic review and meta-analysis of response and resection percentages. PLoS Med. 2010;7(4):e1000267. doi:10.1371/journal.pmed.1000267

5. Giuliani F, Di Maio M, Colucci G, Perrone F. Conventional chemotherapy of advanced pancreatic cancer. Curr Drug Targets. 2012;13(6):795-801. doi:10.2174/138945012800564149

6. Moertel CG. Clinical management of advanced gastrointestinal cancer. Cancer. 1975;36(S2):675-682.

7. Philip PA, Lutz MP. Targeting epidermal growth factor receptorrelated signaling pathways in pancreatic cancer. Pancreas. 2015;44 (7):1046-1052. doi:10.1097/MPA.0000000000000389

8. Roskoski R Jr. The ErbB/HER family of protein-tyrosine kinases and cancer. Pharmacol Res. 2014;79:34-74. doi:10.1016/j.phrs.2013.11.002

9. Thota R, Pauff JM, Berlin JD. Treatment of metastatic pancreatic adenocarcinoma: a review. Oncology. 2014;28(1):6-14.

10. Conroy T, Desseigne F, Ychou M, et al. FOLFIRINOX versus gemcitabine for metastatic pancreatic cancer. $N$ Engl J Med. 2011;364 (19):1817-1825. doi:10.1056/NEJMoa1011923

11. Von Hoff DD, Ervin T, Arena FP, et al. Increased survival in pancreatic cancer with nab-paclitaxel plus gemcitabine. $N$ Engl J Med. 2013;369(18):1691-1703. doi:10.1056/NEJMoa1304369

12. Yamanaka Y, Friess H, Kobrin MS, Buchler M, Beger HG, Korc M. Coexpression of epidermal growth factor receptor and ligands in human pancreatic cancer is associated with enhanced tumor aggressiveness. Anticancer Res. 1993;13(3):565-569.

13. Zhang L, Gu F, Chan J, Wang A, Langer R, Farokhzad O. Nanoparticles in medicine: therapeutic applications and developments. Clin Pharmacol Ther. 2008;83(5):761-769. doi:10.1038/sj.clpt.6100400
14. Wang M, Thanou M. Targeting nanoparticles to cancer. Pharmacol Res. 2010;62(2):90-99. doi:10.1016/j.phrs.2010.03.005

15. Haqq J, Howells LM, Garcea G, Metcalfe MS, Steward WP, Dennison AR. Pancreatic stellate cells and pancreas cancer: current perspectives and future strategies. Eur $J$ Cancer. 2014;50 (15):2570-2582. doi:10.1016/j.ejca.2014.06.021

16. Apte MV, Wilson JS, Lugea A, Pandol SJ. A starring role for stellate cells in the pancreatic cancer microenvironment. Gastroenterology. 2013;144(6):1210-1219. doi:10.1053/j.gastro.2012.11.037

17. Nedaeinia R, Avan A, Manian M, Salehi R, Ghayour-Mobarhan M. EGFR as a potential target for the treatment of pancreatic cancer: dilemma and controversies. Curr Drug Targets. 2014;15 (14):1293-1301. doi:10.2174/1389450115666141125123003

18. Karandish F, Mallik S. Biomarkers and targeted therapy in pancreatic cancer. Biomark Cancer. 2016;8:27-35. doi:10.4137/BiC.s34414

19. Martin-Fernandez ML, Clarke DT, Roberts SK, Zanetti-Domingues LC, Gervasio FL. Structure and dynamics of the EGF receptor as revealed by experiments and simulations and its relevance to non-small cell lung cancer. Cells. 2019;8(4):316. doi:10.3390/cells8040316

20. Citri A, Yarden Y. EGF-ERBB signalling: towards the systems level. Nat Rev Mol Cell Biol. 2006;7(7):505. doi:10.1038/nrm1962

21. Chaturvedi P, Singh AP, Chakraborty S, et al. MUC4 mucin interacts with and stabilizes the HER2 oncoprotein in human pancreatic cancer cells. Cancer Res. 2008;68(7):2065-2070. doi:10.1158/0008-5472. CAN-07-6041

22. Seshacharyulu P, Ponnusamy MP, Haridas D, Jain M, Ganti AK, Batra SK. Targeting the EGFR signaling pathway in cancer therapy. Expert Opin Ther Targets. 2012;16(1):15-31. doi:10.1517/14728222.2011.648617

23. Pereira NB, Do Carmo AC, Diniz MG, Gomez RS, Gomes DA, Gomes CC. Nuclear localization of epidermal growth factor receptor (EGFR) in ameloblastomas. Oncotarget. 2015;6(12):9679-9685. doi:10.18632/oncotarget.3919

24. De Luca A, Carotenuto A, Rachiglio A, et al. The role of the EGFR signaling in tumor microenvironment. J Cell Physiol. 2008;214 (3):559-567. doi:10.1002/jcp. 21260

25. Ardito CM, Grüner BM, Takeuchi $\mathrm{KK}$, et al. EGF receptor is required for KRAS-induced pancreatic tumorigenesis. Cancer Cell. 2012;22(3):304-317. doi:10.1016/j.ccr.2012.07.024

26. Cook N, Frese KK, Moore M. Assessing the role of the EGF receptor in the development and progression of pancreatic cancer. Gastrointest Cancer Targets Ther. 2014;4:23-37.

27. Hackeng WM, Hruban RH, Offerhaus GJA, Brosens LA. Surgical and molecular pathology of pancreatic neoplasms. Diagn Pathol. 2016;11(1):47. doi:10.1186/s13000-016-0497-z

28. Barton CM, Hall PA, Hughes CM, Gullick WJ, Lemoine NR. Transforming growth factor alpha and epidermal growth factor in human pancreatic cancer. $J$ Pathol. 1991;163((2):):111-116. doi:10.1002/path.1711630206

29. Tzeng CD, Frolov A, Frolova N, et al. Epidermal growth factor receptor (EGFR) is highly conserved in pancreatic cancer. Surgery. 2007;141(4):464-469. doi:10.1016/j.surg.2006.09.009

30. Valsecchi ME, McDonald M, Brody JR, et al. Epidermal growth factor receptor and insulinlike growth factor 1 receptor expression predict poor survival in pancreatic ductal adenocarcinoma. Cancer. 2012;118(14):3484-3493. doi:10.1002/cncr.26661

31. Faloppi L, Andrikou K, Cascinu S. Cetuximab: still an option in the treatment of pancreatic cancer? Expert Opin Biol Ther. 2013;13 (5):791-801. doi:10.1517/14712598.2013.786697

32. Moore MJ, Goldstein D, Hamm J, et al. Erlotinib plus gemcitabine compared with gemcitabine alone in patients with advanced pancreatic cancer: a phase III trial of the National Cancer Institute of Canada Clinical Trials Group. J Clin Oncol. 2007;25(15):1960-1966. doi:10.1200/JCO.2006.07.9525

33. Cohenuram M, Saif MW. Epidermal growth factor receptor inhibition strategies in pancreatic cancer: past, present and the future. JOP. 2007;8(1):4-15. 
34. Deshpande PP, Biswas S, Torchilin VP. Current trends in the use of liposomes for tumor targeting. Nanomedicine. 2013;8(9):1509-1528. doi:10.2217/nnm.13.118

35. Cohen S, Carpenter G, King L Jr. Epidermal growth factor-receptorprotein kinase interactions. Co-Purification of Receptor and Epidermal Growth Factor-Enhanced Phosphorylation Activity. J Biol Chem. 1980;255(10):4834-4842.

36. Conte A, Sigismund S. Chapter six-the ubiquitin network in the control of EGFR endocytosis and signaling. In: Teplow DB, editor Progress in Molecular Biology and Translational Science. Vol. 141. Elsevier; 2016:225-276.

37. Edwin F, Wiepz GJ, Singh R, Peet CR, Chaturvedi D, Patel TB. A historical perspective of the EGF receptor and related systems.. In: Patel TB, Bertics PJ, editors. Epidermal Growth Factor. Springer; 2006:1-24.

38. Roepstorff K, Grandal MV, Henriksen L, et al. Differential effects of EGFR ligands on endocytic sorting of the receptor. Traffic. 2009;10 (8):1115-1127. doi:10.1111/j.1600-0854.2009.00943.x

39. Siwak DR, Carey M, Hennessy BT, et al. Targeting the epidermal growth factor receptor in epithelial ovarian cancer: current knowledge and future challenges. J Oncol. 2010;2010:568938. doi:10.1155/ 2010/568938

40. Tzahar E, Waterman H, Chen X, et al. A hierarchical network of interreceptor interactions determines signal transduction by Neu differentiation factor/neuregulin and epidermal growth factor. Mol Cell Biol. 1996;16(10):5276-5287. doi:10.1128/mcb.16.10.5276

41. Wee P, Wang Z. Epidermal growth factor receptor cell proliferation signaling pathways. Cancers. 2017;9(5):52.

42. Hu CD, Kariya K, Tamada M, et al. Cysteine-rich region of Raf-1 interacts with activator domain of post-translationally modified Ha-Ras. $J$ Biol Chem. 1995;270(51):30274-30277. doi:10.1074/jbc.270.51.30274

43. Roy S, Lane A, Yan J, McPherson R, Hancock JF. Activity of plasma membrane-recruited Raf-1 is regulated by Ras via the Raf zinc finger. J Biol Chem. 1997;272(32):20139-20145. doi:10.1074/jbc.272.32.20139

44. Roberts PJ, Der CJ. Targeting the Raf-MEK-ERK mitogen-activated protein kinase cascade for the treatment of cancer. Oncogene. 2007;26(22):3291. doi:10.1038/sj.onc. 1210422

45. Dibble CC, Cantley LC. Regulation of mTORC1 by PI3K signaling. Trends Cell Biol. 2015;25(9):545-555. doi:10.1016/j.tcb.2015.06.002

46. Bjorge JD, Chan TO, Antczak M, Kung HJ, Fujita DJ. Activated type I phosphatidylinositol kinase is associated with the epidermal growth factor (EGF) receptor following EGF stimulation. Proc Natl Acad Sci U S A. 1990;87(10):3816-3820. doi:10.1073/pnas.87.10.3816

47. Cheng JQ, Ruggeri B, Klein WM, et al. Amplification of AKT2 in human pancreatic cells and inhibition of AKT2 expression and tumorigenicity by antisense RNA. Proc Natl Acad Sci USA. 1996;93(8):3636-3641. doi:10.1073/pnas.93.8.3636

48. Peterson TR, Laplante M, Thoreen CC, et al. DEPTOR is an mTOR inhibitor frequently overexpressed in multiple myeloma cells and required for their survival. Cell. 2009;137(5):873-886. doi:10.1016/ j.cell.2009.03.046

49. Patra CR, Bhattacharya R, Mukhopadhyay D, Mukherjee P. Fabrication of gold nanoparticles for targeted therapy in pancreatic cancer. Adv Drug Deliv Rev. 2010;62(3):346-361. doi:10.1016/j. addr.2009.11.007

50. Jain RK. Delivery of molecular and cellular medicine to solid tumors. Adv Drug Deliv Rev. 2012;64::353-365. doi:10.1016/j.addr.2012.09.011

51. Brigger I, Dubernet C, Couvreur P. Nanoparticles in cancer therapy and diagnosis. Adv Drug Deliv Rev. 2012;64:24-36. doi:10.1016/j. addr.2012.09.006

52. Byrne JD, Betancourt T, Brannon-Peppas L. Active targeting schemes for nanoparticle systems in cancer therapeutics. Adv Drug Deliv Rev. 2008;60(15):1615-1626. doi:10.1016/j.addr.2008.08.005

53. Cho K, Wang X, Nie S, Chen ZG, Shin DM. Therapeutic nanoparticles for drug delivery in cancer. Clin Cancer Res. 2008;14 (5):1310-1316. doi:10.1158/1078-0432.CCR-07-1441
54. Martinelli C, Pucci C, Ciofani G. Nanostructured carriers as innovative tools for cancer diagnosis and therapy. APL Bioeng. 2019;3 (1):011502. doi:10.1063/1.5079943

55. Mout R, Moyano DF, Rana S, Rotello VM. Surface functionalization of nanoparticles for nanomedicine. Chem Soc Rev. 2012;41 (7):2539-2544. doi:10.1039/c2cs15294k

56. Ma N, Ma C, Li C, et al. Influence of nanoparticle shape, size, and surface functionalization on cellular uptake. J Nanosci Nanotechnol. 2013;13(10):6485-6498. doi:10.1166/jnn.2013.7525

57. Lu HS, Chai JJ, Li M, Huang BR, He CH, Bi RC. Crystal structure of human epidermal growth factor and its dimerization. J Biol Chem. 2001;276(37):34913-34917. doi:10.1074/jbc.M102874200

58. Master AM, Sen Gupta A. EGF receptor-targeted nanocarriers for enhanced cancer treatment. Nanomedicine. 2012;7(12):1895-1906. doi:10.2217/nnm.12.160

59. Bhirde AA, Patel V, Gavard J, et al. Targeted killing of cancer cells in vivo and in vitro with EGF-directed carbon nanotube-based drug delivery. ACS Nano. 2009;3(2):307-316. doi:10.1021/nn800551s

60. Tseng C, Wu SY, Wang W, et al. Targeting efficiency and biodistribution of biotinylated-EGF-conjugated gelatin nanoparticles administered via aerosol delivery in nude mice with lung cancer. Biomaterials. 2008;29 (20):3014-3022. doi:10.1016/j.biomaterials.2008.03.033

61. Shimada T, Ueda M, Jinno H, et al. Development of targeted therapy with paclitaxel incorporated into EGF-conjugated nanoparticles. Anticancer Res. 2009;29(4):1009-1014.

62. Sandoval MA, Sloat BR, Lansakara-P DS, et al. EGFR-targeted stearoyl gemcitabine nanoparticles show enhanced anti-tumor activity. J Control Release. 2012;157(2):287-296. doi:10.1016/j. jconrel.2011.08.015

63. Song L, Falzone N, Vallis KA. EGF-coated gold nanoparticles provide an efficient nano-scale delivery system for the molecular radiotherapy of EGFR-positive cancer. Int $J$ Radiat Biol. 2016;92 (11):716-723. doi:10.3109/09553002.2016.1145360

64. Shevtsov MA, Nikolaev BP, Yakovleva LY, et al. Superparamagnetic iron oxide nanoparticles conjugated with epidermal growth factor (SPION-EGF) for targeting brain tumors. Int $J$ Nanomedicine. 2014;9:273-287. doi:10.2147/IJN.S55118

65. Creixell M, Herrera AP, Ayala V, et al. Preparation of epidermal growth factor (EGF) conjugated iron oxide nanoparticles and their internalization into colon cancer cells. J Magn Magn Mater. 2010;322(15):2244-2250. doi:10.1016/j.jmmm.2010.02.019

66. Le UM, Hartman A, Pillai G. Enhanced selective cellular uptake and cytotoxicity of epidermal growth factor-conjugated liposomes containing curcumin on EGFR-overexpressed pancreatic cancer cells. J Drug Target. 2018;26(8):676-683. doi:10.1080/1061186X.20 17.1408114

67. Kim W, Na K, Lee K, Lee HW, Lee JK, Kim K. Selective uptake of epidermal growth factor-conjugated gold nanoparticle (EGF-GNP) facilitates non-thermal plasma (NTP)-mediated cell death. Sci Rep. 2017;7(1):10971. doi:10.1038/s41598-017-11292-z

68. Silva CO, Petersen SB, Reis CP, et al. EGF functionalized polymer-coated gold nanoparticles promote EGF photostability and EGFR internalization for photothermal therapy. PLoS One. 2016;11 (10):e0165419. doi:10.1371/journal.pone.0165419

69. Karmakar A, Iancu C, Bartos DM, et al. Raman spectroscopy as a detection and analysis tool for in vitro specific targeting of pancreatic cancer cells by EGF-conjugated, single-walled carbon nanotubes. J Appl Toxicol. 2012;32(5):365-375. doi:10.1002/jat.v32.5

70. Wu L, Yu X, Feizpour A, Reinhard BM. Nanoconjugation: a materials approach to enhance epidermal growth factor induced apoptosis. Biomater Sci. 2014;2(2):156-166. doi:10.1039/C3BM60 $142 \mathrm{~K}$

71. Pan Y, Leifert A, Ruau D, et al. Gold nanoparticles of diameter 1.4 $\mathrm{nm}$ trigger necrosis by oxidative stress and mitochondrial damage. Small. 2009;5(18):2067-2076. doi:10.1002/smll.v5:18 
72. Khanehzar A, Fraire JC, Xi M, et al. Nanoparticle-cell interactions induced apoptosis: a case study with nanoconjugated epidermal growth factor. Nanoscale. 2018;10(14):6712-6723. doi:10.1039/C8NR01106K

73. Sorkin A, Goh LK. Endocytosis and intracellular trafficking of ErbBs. Exp Cell Res. 2009;315(4):683-696. doi:10.1016/j.yexcr.2008.07.029

74. Rush JS, Quinalty LM, Engelman L, Sherry DM, Ceresa BP. Endosomal accumulation of the activated epidermal growth factor receptor (EGFR) induces apoptosis. J Biol Chem. 2012;287 (1):712-722. doi:10.1074/jbc.M111.294470

75. Wu L, Xu F, Reinhard B. Nanoconjugation prolongs endosomal signaling of the epidermal growth factor receptor and enhances apoptosis. Nanoscale. 2016;8(28):13755-13768. doi:10.1039/C6NR02974D

76. Manzur A, Oluwasanmi A, Moss D, Curtis A, Hoskins C. Nanotechnologies in pancreatic cancer therapy. Pharmaceutics. 2017;9(4):39. doi:10.3390/pharmaceutics9040039

77. Wang L, Liu X, Zhou Q, et al. Terminating the criminal collaboration in pancreatic cancer: nanoparticle-based synergistic therapy for overcoming fibroblast-induced drug resistance. Biomaterials. 2017;144:105-118. doi:10.1016/j.biomaterials.2017.08.002
78. Arachchige MP, Laha SS, Naik AR, Lewis KT, Naik R, Jena BP. Functionalized nanoparticles enable tracking the rapid entry and release of doxorubicin in human pancreatic cancer cells. Micron. 2017;92:25-31. doi:10.1016/j.micron.2016.10.005

79. Emamzadeh M, Desmaële D, Couvreur P, Pasparakis G. Dual controlled delivery of squalenoyl-gemcitabine and paclitaxel using thermo-responsive polymeric micelles for pancreatic cancer. J Mater Chem B. 2018;6(15):2230-2239. doi:10.1039/C7TB02899G

80. Malekigorji M, Alfahad M, Lin PKT, Jones S, Curtis A, Hoskins C. Thermally triggered theranostics for pancreatic cancer therapy. Nanoscale. 2017;9(34):12735-12745. doi:10.1039/C7NR02751F

81. Oluwasanmi A, Al-Shakarchi W, Manzur A, et al. Diels Alder-mediated release of gemcitabine from hybrid nanoparticles for enhanced pancreatic cancer therapy. J Control Release. 2017;266:355-364.

82. Liu X, Situ A, Kang Y, et al. Irinotecan delivery by lipid-coated mesoporous silica nanoparticles shows improved efficacy and safety over liposomes for pancreatic cancer. ACS Nano. 2016;10 (2):2702-2715. doi:10.1021/acsnano.5b07781
International Journal of Nanomedicine

\section{Publish your work in this journal}

The International Journal of Nanomedicine is an international, peerreviewed journal focusing on the application of nanotechnology in diagnostics, therapeutics, and drug delivery systems throughout the biomedical field. This journal is indexed on PubMed Central, MedLine, CAS, SciSearch ${ }^{\mathbb{R}}$, Current Contents ${ }^{\mathbb{R}} /$ Clinical Medicine,

\section{Dovepress}

Journal Citation Reports/Science Edition, EMBase, Scopus and the Elsevier Bibliographic databases. The manuscript management system is completely online and includes a very quick and fair peer-review system, which is all easy to use. Visit http://www.dovepress.com/ testimonials.php to read real quotes from published authors. 